\title{
Maternal and neonatal complications in macrosomic pregnancies
}

\author{
Rehab Husain Basher ${ }^{1 *}$, Mohmed Soliman Hussien¹, Nuriya Baharie Nessr ${ }^{2}$
}

${ }^{1}$ Faculty of Medicine, Department of Obstetrics and Gynecology, Sebha Medical Center, Libya

${ }^{2}$ Faculty of Medicine, Department of Obstetrics and Gynecology, Zawiya Teaching Hospital, Libya

Received: 20 May 2019

Accepted: 01 July 2019

\section{*Correspondence:}

Dr. Rehab Husain Basher,

E-mail: researchbhrc@gmail.com

Copyright: () the author(s), publisher and licensee Medip Academy. This is an open-access article distributed under the terms of the Creative Commons Attribution Non-Commercial License, which permits unrestricted non-commercial use, distribution, and reproduction in any medium, provided the original work is properly cited.

\section{ABSTRACT}

Background: Fetal macrosomia is a common problem in obstetrics which leads to morbidity and mortality to both mothers as well as to the new-born due to complications of fetal macrosomia like prolonged labour, operative delivery, postpartum haemorrhage, perineal trauma, shoulder dystocia, birth trauma, perinatal asphyxia and perinatal mortality. This prospective study was conducted on fetal macrosomia to help future identification of such pregnancies, anticipate complications and to plan proper management.

Methods: Maternal, fetal and neonatal consequences of macrosomia with specific attention to etiology of macrosomia in 170 pregnant women having gestational age of 37 weeks or more and high risk of fetal macrosomia were studied. Clinical estimation of fetal body weight was done using Leopold's maneuvers and patient then referred for ultrasonography. Data was collected about mode of delivery, nature and severity of birth trauma.

Results: It was found that maternal age (51.76\%), multiparity $(61.76 \%)$, maternal diabetes $(20.59 \%)$ was significantly associated with macrosomia. Total caesarean rate in macrosomia was $26.4 \%$. We got only 8 cases of birth trauma out of 170 macrosomic births.

Conclusions: Pregnancies complicated by fetal macrosomia can be best managed by giving a trial of labour for babies with fetal weight below 5000 gram. Post gestation, multiparity found to be main risk factor for macrosomia.

Keywords: Caesarean section, Fetal macrosomia, Fetal birth trauma, Large for gestational age, Perineal trauma, Shoulder dystocia

\section{INTRODUCTION}

Fetal macrosomia is very common obstetrics problem. It involves morbidity and mortality to both mothers as well as to new-born. Worldwide incidence of the fetal macrosomia is seen to be increasing. ${ }^{1,2}$

Several risk factors for fetal macrosomia have been identified. The risk factors include multiparity, maternal diabetes, prolonged gestation, excessive weight gain during pregnancy, male sex and high pre-pregnancy body mass index..$^{3-5}$
Difficult deliveries and fetal distress due to cephalopelvic disproportion during labour are frequently seen in macrosomic infants. Maternal complications are related to cephalo-pelvic disproportion include increased risk of prolonged labour, perineal lacerations, postpartum hemorrhage, thromboembolic events, caesarean section and anesthesia events, infection. ${ }^{6,7}$ This risk increases as the birth weight of the infant increases. ${ }^{8}$ Macrosomic infants are at increased risk of perinatal asphyxia, birth trauma like shoulder dystocia, brachial plexus injury, skeletal injuries, meconium aspiration and hypoglycemia and fetal death. ${ }^{9-11}$ 
The maternal and infant complications lead to different opinions regarding management of labour in macromia. So decisions are taken during intrapartum because of difficulty in predicting macrosomia. ${ }^{12}$ Very few studies are done on macrosomia related to the risk factors, maternal outcome and management of labour. Studies are less about the macrosomic infants even though they are at high risk of perinatal morbidity and mortality. Hence this study was conducted on fetal macrosomia so as to aid in future identification of these pregnancies, anticipate their complications and to plan on proper mode of management. So in this study screening was done for pregnancies at higher risk for macrosomia and maternal, fetal and neonatal consequences of macrosomia were studied with specific attention to the potential etiology of macrosomia, birth trauma and mode of deliveries.

\section{METHODS}

The present prospective study conducted in Obstetrics and Gynecology department in Sebha Medical Center, Libya between January 2012 and June 2012. In this period after screening 1800 pregnant women, 170 pregnant women were selected for the study having gestational age of 37 weeks or more and who were at high risk of fetal macrosomia based on the presence of one or more of certain risk factors like gestational diabetes mellitus, pre-existing diabetes mellitus, prolonged gestation, previous delivery of macrosomic baby, advanced age and multiparity. Patients either presented in early labour or for induction of labour.

The inclusion criteria were those with singleton pregnancy regardless to maternal age, number of parity, type of previous delivery and only those patients who were agree to participate in the study. The gestational age was considered from last menstrual period if woman having regular menstrual cycle. Otherwise early ultrasonographic estimation of the gestational age was done.

In the study, birth weight $\geq 4000$ gram to describe fetal macrosomia was used. Leopold's maneuver with fundal height measurement was used for the prenatal diagnosis of possible macrosomia. It has sensitivity of $10-43 \%$, specificity of $99-99.8 \%$ and positive predictive values of $28-53 \%{ }^{13}$

General examinations including maternal body weight and height was performed after obtaining written informed consent from the patients. Blood sample for measuring 2 hours post prandial blood sugar was collected. Clinical estimation of fetal body weight was done using Leopold's maneuvers and patient then referred for ultrasonography. Data was collected about mode of delivery, nature and severity of birth trauma.

Birth trauma was categorized as Erb's palsy, sixth nerve palsy, fracture clavicle and minor birth trauma as soft tissue laceration, ecchymosis and cut wounds.

\section{Statistical analysis}

Data was analyzed on a computer using SPSS (Statistical Package for Social Sciences) version 15.0. Descriptive statistics like percentage were computed for data presentation. Microsoft excel was used to create graphs and tables.

\section{RESULTS}

The actual number of patients and percentage of maternal risk factors for macrosomia was showed in Table 1. High parity was the most common risk factor for macrosomia and large for gestational age was the least common risk factor for macrosomia.

Table 1: Maternal risk factors for macrosomia.

\begin{tabular}{|lll|}
\hline Characteristics & Number & Percentage \\
\hline Diabetes mellitus & 35 & 20.59 \\
\hline Obesity & 40 & 23.53 \\
\hline Large for gestational age & 14 & 8.24 \\
\hline$\geq 41$ week gestation & 37 & 21.76 \\
\hline$\geq 42$ week gestation & 44 & 25.88 \\
\hline Previous macrosomia & 65 & 38.24 \\
\hline High parity & 105 & 61.76 \\
\hline Total & $\mathbf{1 7 0}$ births \\
\hline
\end{tabular}

Table 2: Maternal age as risk factor or macrosomia.

\begin{tabular}{|lll|}
\hline Age & Number & Percentage \\
\hline $15-25$ & 15 & 8.82 \\
\hline $26-34$ & 88 & 51.76 \\
\hline$\geq 35$ & 67 & 39.41 \\
\hline Total & $\mathbf{1 7 0}$ & $\mathbf{1 0 0}$ \\
\hline
\end{tabular}

Table 2 showed the actual number of patients and percentage of different maternal age groups as risk factors for macrosomia. Above table showed increased maternal age (above 26-34 and $\geq 35$ years) is significant risk factor for fetal macrosomia.

Table 3 showed different modes of delivery in macrosomic baby related to birth weight percentage. $76.26 \%$ pregnant women having macrosomic baby weight 4000-4499grams underwent vaginal delivery successfully and $61.29 \%$ pregnant women having macrosomic baby weight $\geq 4.5 \mathrm{~kg}$ underwent vaginal delivery successfully.

Different modes of delivery in macrosomic baby and in normal birth weight babies were showed in Table 4 . $73.53 \%$ pregnant women having macrosomic baby weight 4000-4499 grams underwent vaginal delivery successfully. LSCS was needed only in $26.47 \%$ women with macrosomic babies is not much significantly increased as compared to normal weight baby deliveries needing LSCS of $21.8 \%$. 
Table 3: Mode of delivery in macrosomic baby related to birth weight percentage.

\begin{tabular}{|lllll|}
\hline Mode of delivery & $(\mathbf{4 - 4 . 4 9 9 )}) \mathrm{kg}$ & & $\geq 4.5 \mathrm{~kg}$ & Number \\
\hline Vaginal delivery & Number & Percentage & 19 & Percentage \\
\hline LSCS & 106 & 76.26 & 12 & 38.71 \\
\hline Total & 33 & 23.74 & $\mathbf{3 1}$ & $\mathbf{1 0 0}$ \\
\hline
\end{tabular}

Table 4: Mode of total deliveries in the hospital.

\begin{tabular}{|c|c|c|c|c|}
\hline \multicolumn{5}{|l|}{ Total $=1800$ births } \\
\hline \multirow{2}{*}{ Mode of delivery } & \multicolumn{2}{|c|}{ Total No $=170$ births $4000-4999 \mathrm{~g}$} & \multicolumn{2}{|c|}{ Total $\mathrm{No}=1630$ births $2500-3999 \mathrm{~g}$} \\
\hline & Number & Percentage & Number & Percentage \% \\
\hline Vaginal delivery & 125 & 73.53 & 1275 & 78.2 \\
\hline LSCS & 45 & 26.47 & 355 & 21.8 \\
\hline Total & 170 & 100 & 1630 & 100 \\
\hline
\end{tabular}

Table 5 showed cephalo-pelvic disproportion (53.33\%) was the commonest indication for LSCS. Previous LSCS was the indication for $31.11 \%$ of macrosomic deliveries. Only 7 cases $(15.56 \%)$ had other indications like malpresentation, fetal distress.

Table 5: The indication of cesarean section in macrosomic babies.

\begin{tabular}{|lll|}
\hline Indication of LSCS & Number & Percentage \\
\hline Cephalo-pelvic disproportion & 24 & 53.33 \\
\hline Previous LSCS & 14 & 31.11 \\
\hline Other & 7 & 15.56 \\
\hline Total & $\mathbf{4 5}$ & $\mathbf{1 0 0}$ \\
\hline
\end{tabular}

Table 6: Maternal birth trauma due to macrosomia.

\begin{tabular}{|lll|}
\hline Total number of vaginal delivery $\mathbf{1 2 5}$ births \\
\hline Parameter & Number & Percentage \\
\hline 4th degree vaginal tear & 0 & 0 \\
\hline Total & $\mathbf{0}$ & $\mathbf{0}$ \\
\hline
\end{tabular}

Table 6 showed there was no maternal trauma due to macrosomia in 125 vaginal deliveries. There were 0 cases of 4th degree vaginal tear. This finding indicates safe vaginal delivery is possible in macrosomia and less maternal risk.

Table 7: Neonatal birth trauma due to macrosomia.

\begin{tabular}{|lll|}
\hline Total Number of vaginal delivery & $\mathbf{1 2 5}$ births \\
\hline Fetal birth trauma & Number & Percentage \\
\hline Clavicle fracture & 2 & 0.02 \\
\hline Erb's palsy & 6 & 0.05 \\
\hline 6th nerve palsy & 0 & 0 \\
\hline Laceration wound & 0 & 0 \\
\hline
\end{tabular}

Table 7 showed out of total 125 vaginal deliveries, there were 2 cases of clavicle fracture $(0.02 \%)$ and 6 cases of
Erb's palsy $(0.05 \%)$ in macrosomia even during vaginal deliveries. There were 0 cases of 6 th nerve palsy and laceration wound reported. Neonatal birth trauma risk was found to be very less in vaginal deliveries in macrosomia.

Table 8: The incidence of birth trauma in relation to birth weight.

\begin{tabular}{|llll|}
\hline \multicolumn{4}{|c|}{ Total number of vaginal delivery 125 births } \\
\hline & $(4-4.499) \mathrm{kg}$ & $\geq 4.5 \mathrm{~kg}$ & $\mathrm{p}$-value \\
\hline Clavicle fracture & 2 & 0 & $0.34 \mathrm{~ns}$ \\
\hline Erb's palsy & 4 & 2 & $.025 \mathrm{~ns}$ \\
\hline
\end{tabular}

Table 8 showed comparison of incidence fetal birth trauma between (4-4.499) kg fetal weight group and $\geq 4.5 \mathrm{~kg}$ fetal weight group of macrosomia groups. Incidence of birth trauma is not significantly different in both the groups. The incidence of Erb's palsy in the group of macrosomic babies weighting 4000-4499 grams was more as compared to other subgroup of macrosomic babies weighting $>4500$ grams.

\section{DISCUSSION}

In the present study, $51.76 \%$ of mothers having macrosomic infants were in the age group of 34-26 years and $39.41 \%$ mothers having macrosomic infants were in the group of 35 years and above. This finding was similar to the study done by Essel et al in South Africa. ${ }^{14}$ This might be due to high maternal age which causes effect on maternal metabolism leading to increased growth velocity in the fetus.

In the present study $21.76 \%$ women having pregnancy duration greater than 41 weeks had fetal macrosomia and $25.88 \%$ women having pregnancy duration 42 weeks gestation had fetal macrosomia. This finding was also observed by Cheng et al. ${ }^{4}$ 
In the study finding maternal diabetes rate among macrosomia was $20.59 \%$. Diabetes in this group may be associated with obesity and thus greater insulin resistance, resulting in increased glucose availability to the fetus. Moreover, even mothers without gestational diabetes mellitus have minor abnormalities in glucose metabolism during early and late gestation. Minor abnormalities in glucose metabolism has been linked to increase the risk of fetal overgrowth. ${ }^{15}$

The high risk triad which includes obesity, diabetes and post gestation seen in our study was same with the study done by WN Spellacy. ${ }^{16}$

In the study high parity was the major risk factor for macrosomia. Multiparity was significantly associated with macrosomia group $61.76 \%$. Multiparity is associated with decreased insulin sensitivity. This leads to more amount of glucose being available for placental glucose transport. This results in greater adipose tissue deposition in the fetus. ${ }^{10}$

The study data showed prevalence of brachial plexus injury, clavicle fracture among macrosomic neonates was $0.05 \%, 0.02 \%$, respectively.

Cesarean section ensures avoiding trauma to the fetus but can increase the risk of morbidity in the mother. ${ }^{17}$ This safest mode of delivery is controversial with some evidence favoring elective cesarean section. ${ }^{18}$

The present study showed total caesarean rate in macrosomia was $26.4 \%$ where as it was $22.5 \%$ study conducted by Molaud in Iran. ${ }^{19}$ Common indication for caesarean section in the present study was CephaloPelvic Disproportion. Spellacy has mentioned the amount of caesarean section $33.8 \%$ and instrumental delivery $36 \%$. In this study instrumental delivery was zero because of the liberal use of caesarean section in case of failed spontaneous labour.

$73.53 \%$ pregnant women having macrosomic baby weight 4000 - 4499 grams underwent vaginal delivery successfully. Only $26.47 \%$ pregnant women having macrosomic baby weight 4000 - 4499 grams needed LSCS. In the present study perineal trauma cases reported were zero as compared to $5 \%$ by Kimberly and $4.2 \%$ by Meshari. ${ }^{20 .}$

The present study reported only 8 cases of birth trauma out of 170 macrosomic births. In literature $15 \%$ risk of brachial plexus injuries in the face of shoulder dystocia are reported. The majority of these injuries recover completely but about $20 \%$ have some permanent sequelae.

It was found that the incidence of Erb's palsy in the group of macrosomic babies weighing 4000 - 4499 grams was even more compared to other subgroup of macrosomic babies weighting >4500 grams.

\section{CONCLUSION}

The incidence of birth trauma in the macrosomic babies weighing $\geq 4500$ grams is even equal or less comparing to the other subgroup of macrosomic babies weighing 4000 - 4499 grams.

Pregnancies complicated by fetal macrosomia are best managed expectantly by giving a trial of labour for babies with an estimated fetal weight below 5000 grams.

Postdate and high parity found to be main risk factor for macrosomic infant.

\section{Funding: No funding sources}

Conflict of interest: None declared

Ethical approval: The study was approved by the Institutional Ethics Committee

\section{REFERENCES}

1. Surkan PJ, Hsieh CC, Johansson AL, Dickman PW, Cnattingius S. Reasons for increasing trends in large for gestational age births. Obstet Gynecol. 2004;104:720-6.

2. Onyiriuka AN. High birth weight babies: incidence and foetal outcome in a mission hospital in Benin City, Nigeria. Niger J Clin Pract. 2006;9:114-9.

3. Anoon SS, Rizk DE, Ezimokhai M. Obstetric outcome of excessively overgrown fetuses (>or=5000 g): a case-control study. J Perinat Med. 2003;31:295-301.

4. Cheng YW, Nicholson JM, Nakagawa S, Bruckner TA, Washington AE, Caughey AB. Perinatal outcomes in low-risk term pregnancies: do they differ by week of gestation? Am J Obstet Gynecol. 2008;199:370.

5. Getahun D, Ananth CV, Peltier MR, Salihu HM, Scorza WE. Changes in prepregnancy body mass index between the first and second pregnancies and risk of large-for-gestational-age birth. Am J Obstet Gynecol. 2007;196:530.

6. Kamanu CI, Onwere S, Chigbu B, Aluka C, Okoro O, Obasi M. Fetal macrosomia in African women: a study of 249 cases. Arch Gynecol Obstet. 2009;279:857-61.

7. Jolly MC, Sebire NJ, Harris JP, Regan L, Robinson S. Risk factors for macrosomia and its clinical consequences: a study of 350, 311 pregnancies. Eur J Obstet Gynecol Reprod Biol. 2003;111:9-14.

8. Onwude JL, Rao S, Selo-Ojeme DO. Large babies and unplanned Caesarean delivery. Eur J Obstet Gynecol Reprod Biol. 2005;118:36-9.

9. Zhang X, Decker A, Platt RW, Kramer MS. How big is too big? The perinatal consequences of fetal macrosomia. Am J Obstet Gynecol. 2008;198:517.

10. Catalano PM, Thomas A, Presley HL, Amini SB. Increased fetal adiposity: a very sensitive marker of abnormal in utero development. Am J Obstet Gynecol. 2003;189:1698-701. 
11. Howlim J, Chongtan B, Essa A. Delivery of macrosomic babies. Management and outcomes of 330 cases. J Obstet. Gynaecol. 2002;22:370-4.

12. Rhodes JC, Kenneth C. Contribution of excess weight gain during pregnancy and macrosomia to the caesarean delivery rate. $\mathrm{Br} \mathrm{J}$ Obstet Gynecol. 2003;111:1181-5.

13. Baskett TF, Allen AC. Perinatal implications of shoulder dystocia .Obstet Gynecol. 1995;86:14-7.

14. Essel JK, Tetteh ET. Macrosomia-maternal and fetal risk factors. S Afr Med J. 1995;85:43-6.

15. Mello G, Parretti E, Mecacci F, Lucchetti R, Lagazio C, Pratesi M, et al. Risk factors for fetal macrosomia: the importance of a positive oral glucose challenge test. Eur J Endocrinol. 1997;137:27-33.

16. Spellacy WN, Miller S, Winegar A, Peterson PQ. Macrosomia-maternal characteristics and infant complications. Obstet Gynecol. 1985;66(2):158-61.

17. Conway DL. Choosing route of delivery for the macrosomic infant of a diabetic mother: caesarean section versus vaginal delivery. J Mat Fetal Neonatal Med. 2002;12(6):442-8.

18. Mulik V, Usha TS, Bethal J. The outcome of macrosomic fetuses in a low risk primigravid population. Int J Gynaecol Obstet. 2003;80(1):15-22.

19. Mould F. Studying the relationship between macrosomia \& maternal and infant complications. 25th international congress of Medical Women's International Association. 2000;18:1426.

20. Meshari AA, De-Silva S, Rahman I. Fetal macrosomia - maternal risks and fetal outcome. Int J Gynecol Obstet. 1990;32:215-22.

Cite this article as: Basher RH, Hussien MS, Nessr NB. Maternal and neonatal complications in macrosomic pregnancies. Int J Reprod Contracept Obstet Gynecol 2019;8:3147-51. 